\title{
DE ARMARIOS Y OTRAS COSAS DE CASAS...
}

\author{
María Melgarejo Belenguer \\ Universidad Politécnica de Valencia
}

Recibido 09/02/2011

Aceptado 20/05/2011

\section{Resumen}

Al inicio del siglo XX, durante sus tres primeras décadas, en la arquitectura se produjo un cambio radical y absoluto que no tuvo precedentes, como reflejo de la sociedad. Una ruptura con el pasado y una voluntad decidida de renovación y transformación que arrasó con todo lo conocido y que inició la lucha por la vida moderna

Se estudia en este texto la aportación de dos mujeres: Charlotte Perriand, y Lilly Reich, a la renovación de la arquitectura.

Ambas por su origen y formación, anclada aún en el siglo XIX, conocían bien las restricciones de ese ámbito privado, la casa, al que habían sido relegadas. Sabían qué era necesario en el hogar y cómo organizarlo y lo aplicaron para iniciar la renovación desde el interior de la arquitectura.

Palabras clave: Diseño de interiores, arquitectura, mujeres diseñadoras, la casa moderna.

\begin{abstract}
At the beginning of the twentieth century, during its first three decades, in architecture there was a change radical and all that was unprecedented, reflecting the society. One break with the past and will determination of renewal and transformation that swept all know nand who started the fight for modern life. We study in this paper the contribution of two women: Charlotte Perriand, and Lilly Reich, a renewal of architecture.

Both share origin and training, were still anchored in the XIX century, were aware of the restrictions of this area private house, which had been closed. They Known what was needed at home and how to organize it, and applied to start the renovation from the inside of the architecture.
\end{abstract}

Keywords: Interior Design, Architecture, women designers, Modernism House. 
La imagen de Peter de Höoch, nos muestra, en un primer plano, a dos mujeres frente a un armario, guardando la ropa de la casa, recién lavada, de forma ordenada; en el plano siguiente una niña juega entretenida ajena al quehacer de las mayores.

Esta pintura es un ejemplo bastante característico, de lo que el teórico francés Quatremère de Quincy calificó como "pintura de género», para describir únicamente la pintura de escenas domésticas y de la vida cotidiana. ${ }^{1}$

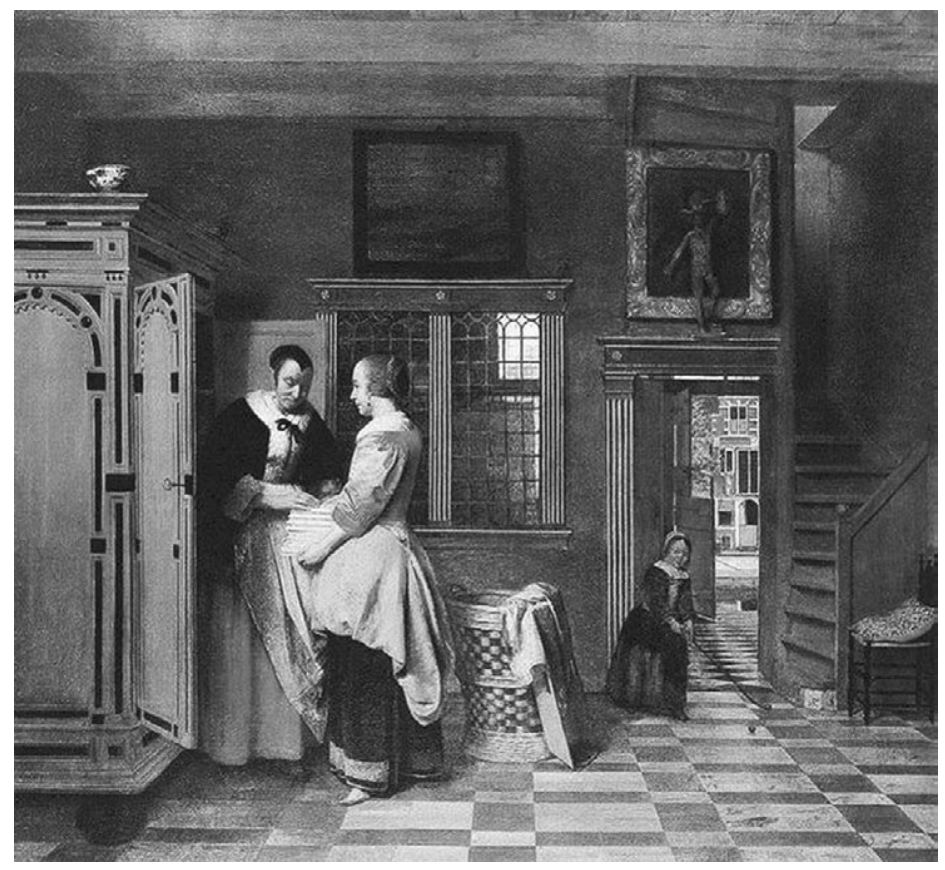

Peter de Höoch. El armario de la ropa blanca. 1663.

(http://www.centroarte.com)

1. Vegara, Alejandro. Vermeer y el interior holandés. Madrid, Museo Nacional del Prado, 2003.

Feminismo/s 17, junio 2011, pp. 213-228 
A partir de 1658, en Holanda, Pieter de Höoch realizó principalmente escenas de interior, con personajes en su mayoría femeninos. En las pinturas con mujeres trabajando, como la que es objeto de análisis, de Hooch idealizó la vida doméstica, de la época. La pintura holandesa del siglo XVII, se centró en la temática de la vida del hogar, donde la mujer era la figura protagonista, y asumía el papel doméstico que correspondía al ideal de la época: las virtudes simples, la correcta administración del hogar, la maternidad y la buena educación de los niños. En el hecho de que las figuras de mujeres predominen en la pintura de interior doméstico, desde 1650, en autores como Pieter de Hooch y Johannes Vermeer se puede encontrar el reflejo de una sociedad que confinaba en el ámbito doméstico a la mujer.

El concepto de vida interior que se estaba desarrollando en ese momento, separaba la vida de la calle, de la vida familiar, apareciendo una incipiente diferenciación de espacios. La casa era el ámbito femenino, el ámbito privado, frente al masculino, que era el público, la calle, el café, el club. La casa se estructuraba reproduciendo estos dos ámbitos, dividiendo los espacios en privados y públicos, en estancias femeninas y masculinas.

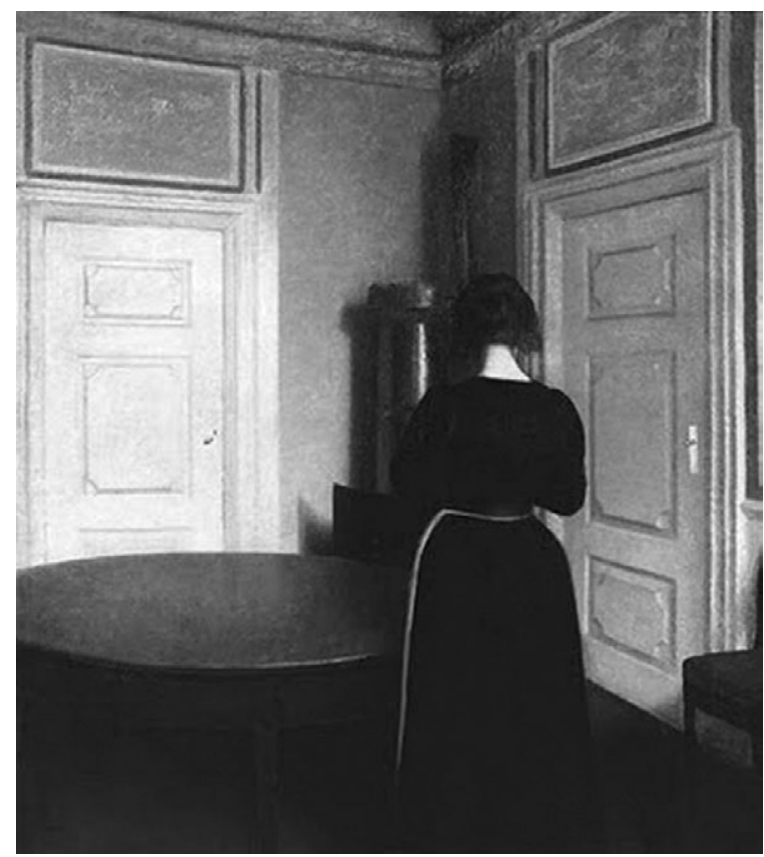

Vilhelm Hammershøi. Muchacha joven cosiendo. 1887. (http://www.uv.es/capelo/Hammershoi.html) 
La correlación entre estructura espacial y estructura social se hará más explícita en el siglo XIX, donde se diferenciarán las posiciones en el espacio de la vivienda según la estructura jerárquica de las relaciones familiares.

Como señala Richard Sennet, en La conciencia del ojo, el hogar era el refugio moral en el que estaban reducidas las mujeres, mientras que a los hombres se les permitía salir a la calle» ${ }^{2}$. El autor hace referencia a un artículo titulado «Una o dos nociones más acerca del bienestar doméstico», que fue publicado en el Appleton's Journal en 1879, en el que un escritor proclamaba:

...Para una mujer el hogar representa la vida militar; para un hombre, la vida del reposo...Ella no dispone de otra esfera en la cual realizar sus actividades...la mujer, por las propias necesidades de su existencia, tiene que tener una idea muy diferente, de la que tiene un hombre. ${ }^{3}$

La mujer en el siglo XIX, tenía la responsabilidad moral y material del hogar. Las tareas domésticas eran su forma de expresión. Su cometido era cuidar del hogar y procurar en él, la vida en familia.

En el periodo comprendido entre los años veinte y la primera década de los años treinta, del siglo XX, se hizo necesaria una ruptura con el pasado y surgió una voluntad decidida de renovación y de transformación, que arrasó con todo lo conocido y que inició la lucha por la vida moderna. En la arquitectura se produjo un cambio radical y absoluto que no tuvo precedentes.

Desde 1921, aproximadamente, el arquitecto Le Corbusier inició sus investigaciones para encontrar una solución al problema de la casa moderna.

Le Corbusier, pronunció una serie de conferencias en Buenos Aires en 1929. En la décima, la que llevaba por título «La aventura del mobiliario», comentó ante una asociación llamada «Los Amigos de las Artes»:

... No se enfocará con eficacia la renovación de la planta de la casa moderna, sino después de haber puesto al desnudo la cuestión del mobiliario. Aquí está el nudo gordiano. Hay que cortarlo, de lo contrario, toda persecución de vida moderna es vana. ${ }^{4}$

En dicha conferencia se declaró obsesionado por la anomalía del mobiliario. También mencionó a Madame Charlotte Perriand, de la que se refirió como «nuestra asociada para el acondicionamiento de los interiores de las casas» 5 . Para acometer la renovación de la casa, Le Corbusier, eligió una mujer.

Por iniciativa de Charlotte Perriand, en el Salon d'Automne de 1929, una exposición que se celebraba anualmente desde 1903 en París, el taller de Le

2. SENNET, Richard. La conciencia del ojo. Barcelona, Versal, 1991.

3. Ibídem, p. 47

4. Le Corbusier. Precisiones. Barcelona, Poseidón, 1979, p. 128.

5. Ibídem, p. 135. 

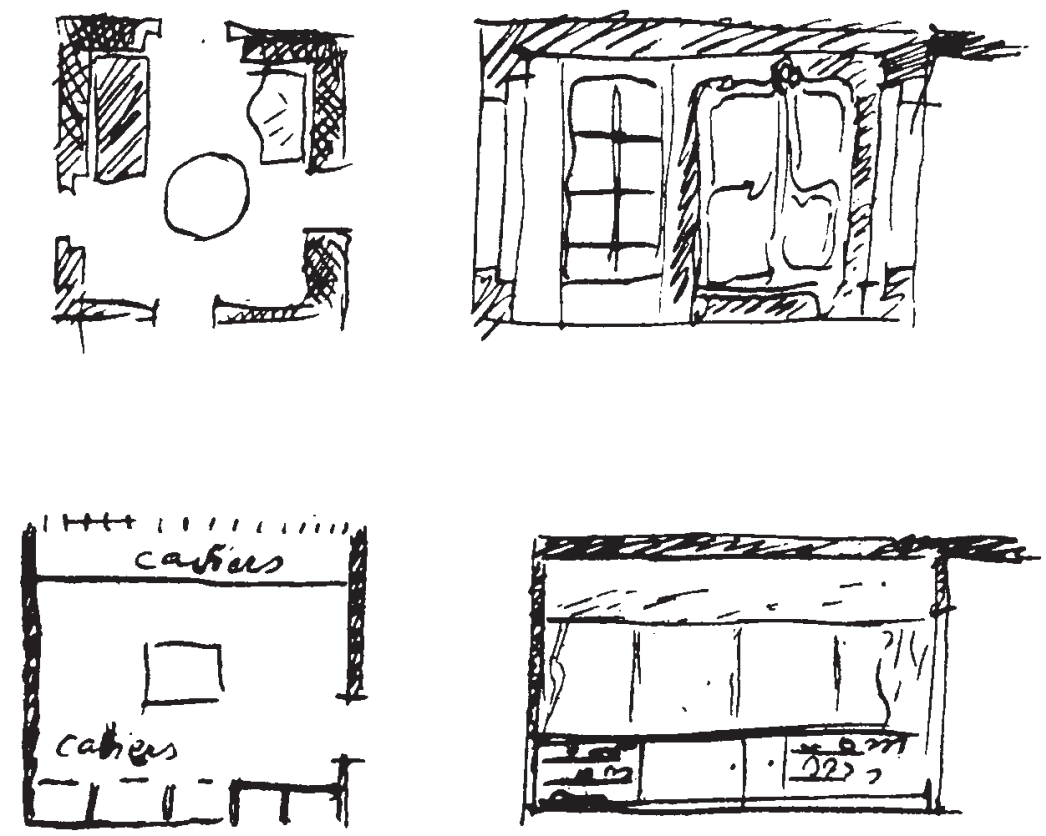

Le Corbusier, dibujos comparados. Dibujo de un plano de amueblamiento y la sección de un dormitorio tradicional con el gran armario normando. Dibujo en plano y en sección de un dispositivo moderno: ventanas, tabiques y casiers. (Le Corbusier: Precisiones. Barcelona, Poseidón, 1979)

Corbusier, construyó un prototipo de vivienda moderna. Por primera vez, el proyecto de arquitectura se iniciaba a partir de la organización y dimensionado del espacio interior y con un nuevo concepto de mobiliario, que adquiriría una nueva denominación Equipamiento.

Charlotte Perriand nació en 1903, su formación había sido en el más puro estilo «Artes Decorativas», la enseñanza que había recibido de los decoradores Maurice Dufrène y de Henri Rapin, conocía muy bien los patrones heredados del siglo XIX, había sido educada en ellos, como ella mismo explicaría en su autobiografía. ${ }^{6}$

Perriand trabajó en el taller de la rue Sèvres, desde su incorporación, a finales de 1927, en el equipamiento para viviendas, al mismo tiempo que desarrollaba el estudio de los casiers, los elementos que iban a resolver el problema del almacenaje, y a sustituir los antiguos «armarios normandos», aquellos grandes muebles.

6. Perriand, Charlotte. Une vie de creation, París, Odile Jacob, 1998. 


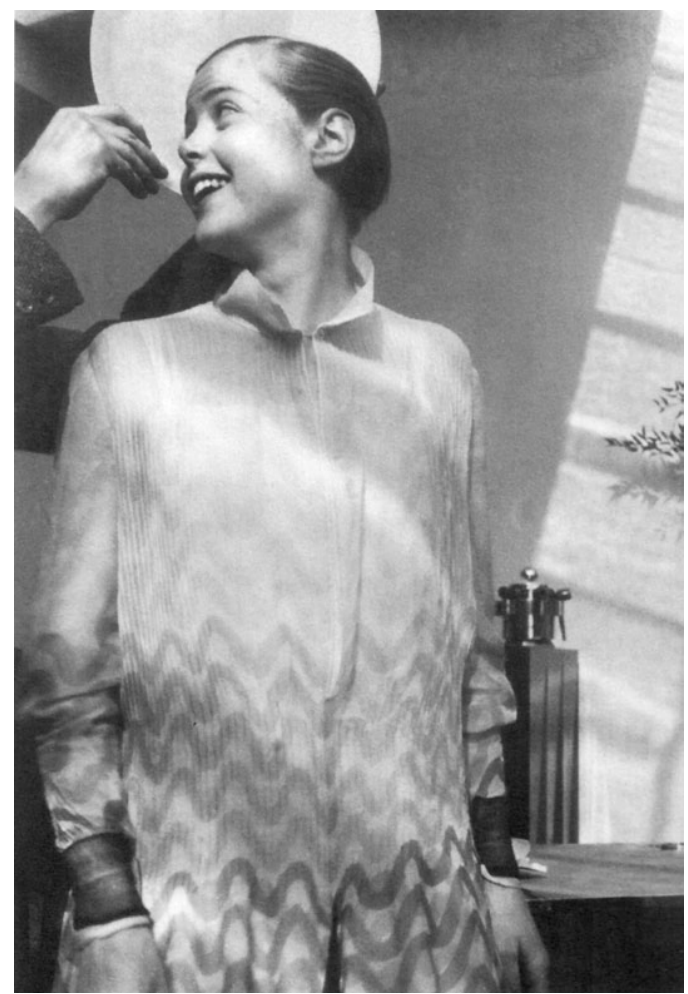

Charlotte Perriand en 1928.

(PERRIAND, Charlotte: Una vie de création. París, Odile Jacob, 1998)

Ella, por su educación, sabía qué era necesario en el hogar y cuánto ocupaba, había sido preparada como todas las mujeres en el siglo XIX, para saber crear un hogar bello y organizado. El almacenaje era definido por Perriand como factor de orden y armonía, estaba convencida de que al lograr resolver este problema, conseguirían la transformación en la vivienda. Para ello, llevó a cabo un proceso exhaustivo de dimensionado de todos los objetos de la vida cotidiana, una camisa plegada, un sombrero, o unos libros... todo fue medido y clasificado.

Todo, hasta el más mínimo detalle, se encontraba registrado en sus «tablas de dimensionado», lo que le permitió establecer unas superficies mínimas, para cada función de la vida doméstica.

De sus conclusiones, obtuvo las necesidades de espacio para las actividades más habituales, del modo de vida previsible, del número de ocupantes y de la relación entre ellos. 


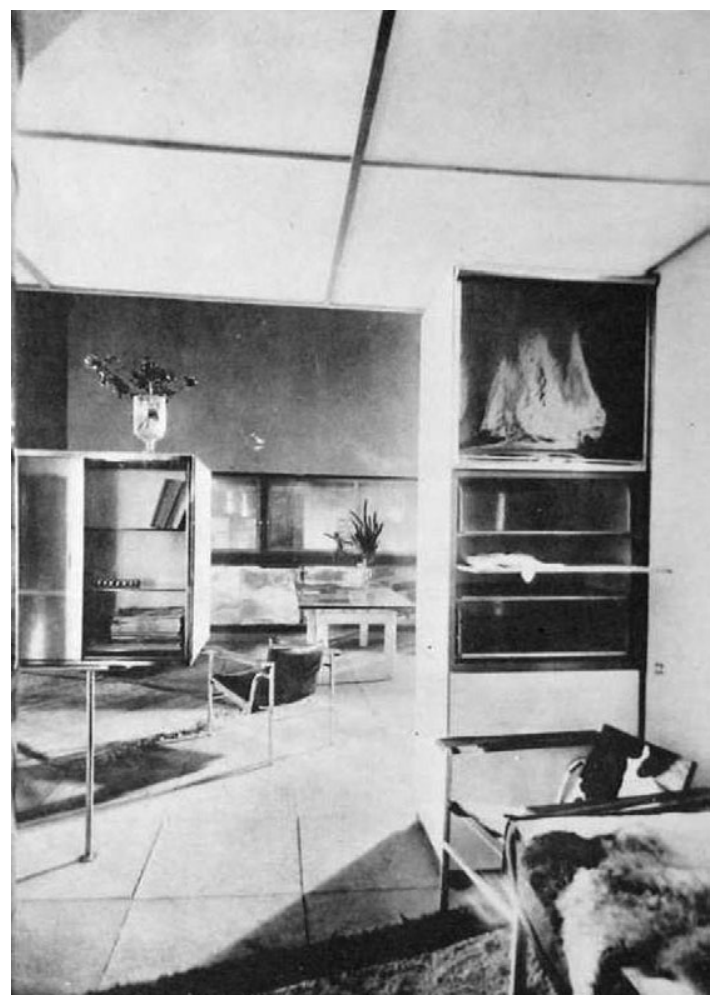

Le Corbusier, Pierre Jeanneret y Charlotte Perriand. Vivienda en el Salon d' automne París. 1929.

(Revista Architecture Vivante 1929)

Y surgió nuevo concepto de organización del espacio interior, sin compartimentaciones estancas, tan sólo por los nuevos elementos de almacenaje, los llamados casiers, a cuyo diseño y producción en serie, Perriand dedicó varios años.

Ya no había muros, el espacio era abierto y flexible, esta nueva configuración llevaba implícita un cambio en el modo de vida, una nueva mentalidad, una redefinición de la estructura jerárquica de los habitantes de la casa, que años más tarde daría lugar a la integración de la cocina abierta, al estar como parte del cambio del papel de la mujer en el hogar. Una muestra de ello fue el mueble - cocina - diseñado para el apartamento de Le Corbusier hacia 1931 y posteriormente adaptado al que diseñó para la Unité d'Habitation de Marseille. La cocina fue diseñada por Perrriand, estaba separada del comedor y de la sala de estar, por una puerta, frente a la que colocó un cuerpo de casiers que 


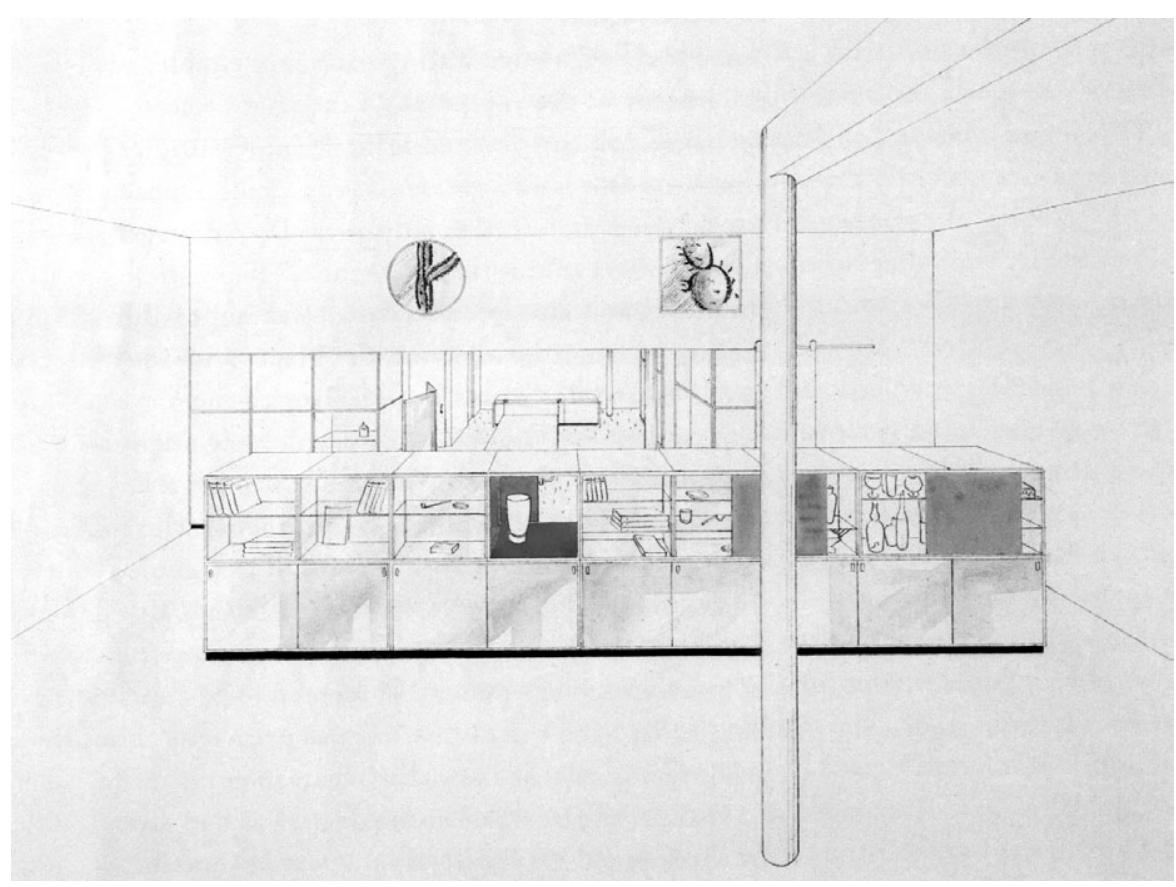

Charlotte Perriand. Vivienda para Julian Martinez de Hoz. 1930

(BARSAC, Jacques: Charlotte Perriand: Un art d'habiter. París, Norma, 2005)

se interrumpía para dejar el espacio libre a la altura de la vista y de las manos, lo que simplificaba aspectos funcionales, como pasar los platos o permitir una mayor comunicación mientras se trabajaba, con el comedor. Está solución ya había sido empleada para la cocina del Salon d' Automne de 1929.

Con sus estudios, Charlotte Perriand resolvía el problema de la vivienda moderna, aquella que Le Corbusier anhelaba, la casa -máquina, exacta y precisa.

Estos principios también fueron aplicados por Perriand al diseñar, en solitario, una vivienda en 1930, para Julián Martinez de Hoz, aunque no fue construida.

Una forma de hacer, que demostraba: «tener una idea muy diferente del hogar de la que tiene un hombre». ${ }^{7}$ La idea de proyectar para una nueva manera de vivir, comenzaba a estar presente en todos los autores del momento. Adolf Behne, crítico, historiador del arte, escritor sobre arte y arquitectura,

7. SENNET, Op. cit., pág. 47. 
vinculado a la Asociación Deutscher Werkbund, insistía en esa idea, y decía que: «La arquitectura no es otra cosa que organizar el espacio de manera que la vida pueda desarrollarse lo mejor posible ${ }^{8}$. La verdadera transformación de la arquitectura sólo podría hacerse cambiando gradualmente los valores de la sociedad y para ello, era necesario renovar el núcleo básico de la misma: la casa.

Desde otra posición, el arquitecto Mies van der Rohe era consciente de esa necesidad. En una carta a la revista Die Form, en 1927, afirmaba que:

La forma como meta desemboca siempre en formalismo.

Un esfuerzo que se orienta hacia el exterior no al interior.

Sólo un interior vivo puede tener un exterior vivo.

Sólo la intensidad vital puede tener intensidad formal

La verdadera forma, presupone una vida verdadera, pero ninguna vida pasada ni tampoco imaginada. ${ }^{9}$

1927 fue el año que podría considerarse como el punto de partida de la verdadera renovación en la arquitectura. Se inició con la exposición La vivienda de la Asociación Deutscher Werkbund, en Stuttgart, y la construcción de un conjunto de viviendas, la colonia Weissenhof. La exposición quería dar respuesta a la pregunta "Wie wohnung» ¿cómo vivir? El arquitecto Mies van der Rohe fue el director de la misma, y en ella inició su colaboración con Lilly Reich.

Lilly Reich nació en 1885, fue estudiante en 1910, en Berlín, de Else Oppler - Legband, en la Fachschule für Dekorationskunst, una diseñadora de vestuario, desde 1904, que había estudiado con los diseñadores y arquitectos, Maximiliano Dasio en Munich, Henry van de Velde en Berlín y Peter Behrens en Nuremberg.

Reich también había estudiado en 1908, en los Wiener Werkstätte, los Talleres Vieneses, como Oppler - Legband, había sido también estudiante de Henry van de Velde, quien alcanzó su prestigio a mediados de 1890 y que en 1904, fue nombrado profesor de la recientemente inaugurada escuela de Artes y Oficios en Weimar, y estuvo también vinculado a la Deutscher Werkbund, de la que Oppler - Legband fue co-fundadora.

Lilly Reich, al igual que Charlotte Perriand, había tenido una educación anclada en el siglo XIX y su formación procedía de las Artes Decorativas. Ambas pertenecían a una minoría selecta de mujeres, que había podido estudiar.

8. Según indica Adolf Behne en Neues Wohnen-Neues Bauen. Citado en Fritz Neumeyer, Mies Van der Rohe, La palabra sin artificio, Reflexiones sobre arquitectura, 1922-1968, Madrid, Croquis, 1995. pág. 278.

9. Íbidem, Fritz Neumeyer, Mies Van der Rohe, pág. 470. 


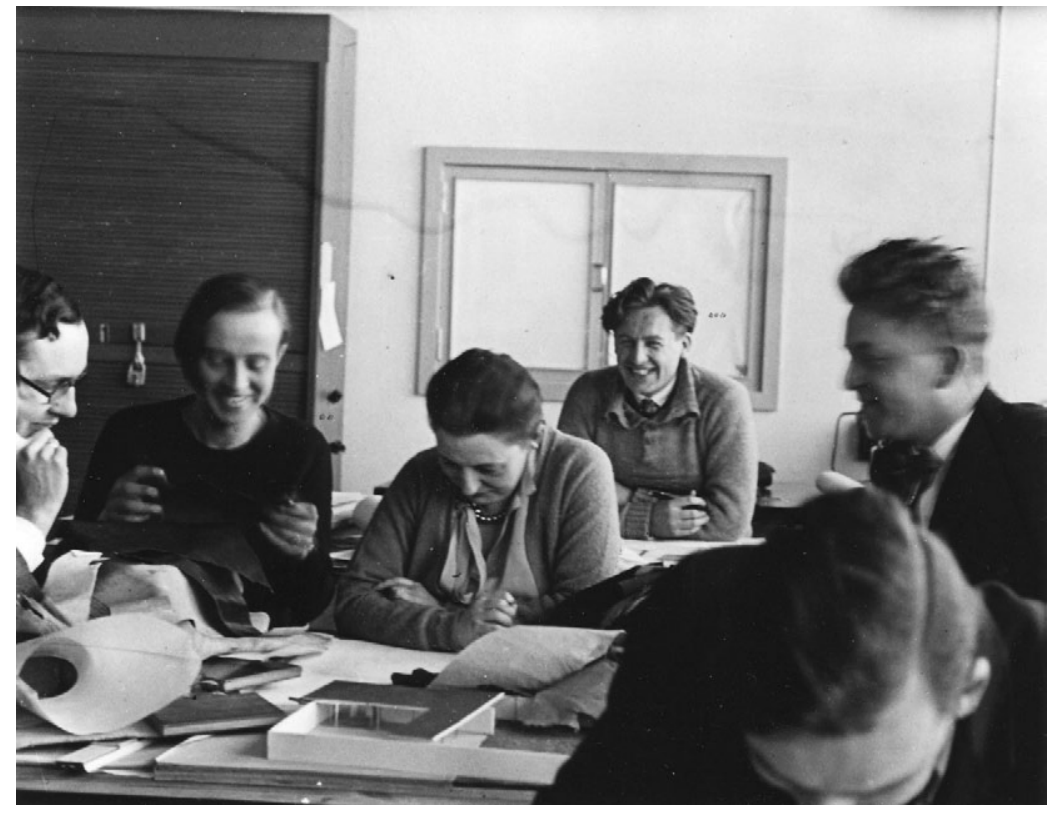

Lilly Reich en 1930.

(Lilly Reich en 1930. Archivo Bauhaus)

1927, fue también el año en el que se consolidó la relación profesional de Mies y Reich, Para amueblar alguno de los apartamentos del bloque construido por Mies van der Rohe en la Weissenhoff, en Stuttgart, en 1927, eligió a Lilly Reich. El concepto de espacio interior de Lilly Reich ya se podía intuir allí; los espacios eran austeros pero agradables. Los elementos elegidos se reducían a lo esencial.

Mies y Reich realizaron juntas, algunos proyectos que marcarían su trayectoria posterior. Entre ellos: el Café Samt und Seide, Café de terciopelo y seda, para la feria Die mode der dame, Moda de mujer, que tuvo lugar en Berlín, entre septiembre y octubre de 1927 y dos instalaciones que realizaron al mismo tiempo en Stuttgart, para la exposición de la Werkbund, la Glass Room, la Sala del Cristal, para la Asociación Alemana de Fabricantes de cristal y el stand contiguo, para la Deutsche Linoleum Werke, Los Fabricantes Alemanes de Linóleo.

Con estos trabajos, Mies y Reich mostraron que la configuración espacial se podía conseguir con otros materiales, que no era necesario definir el espacio con elementos arquitectónicos. Un concepto abstracto para paredes, suelos y techos que se encontraría años más tarde, en los proyectos para la casa 


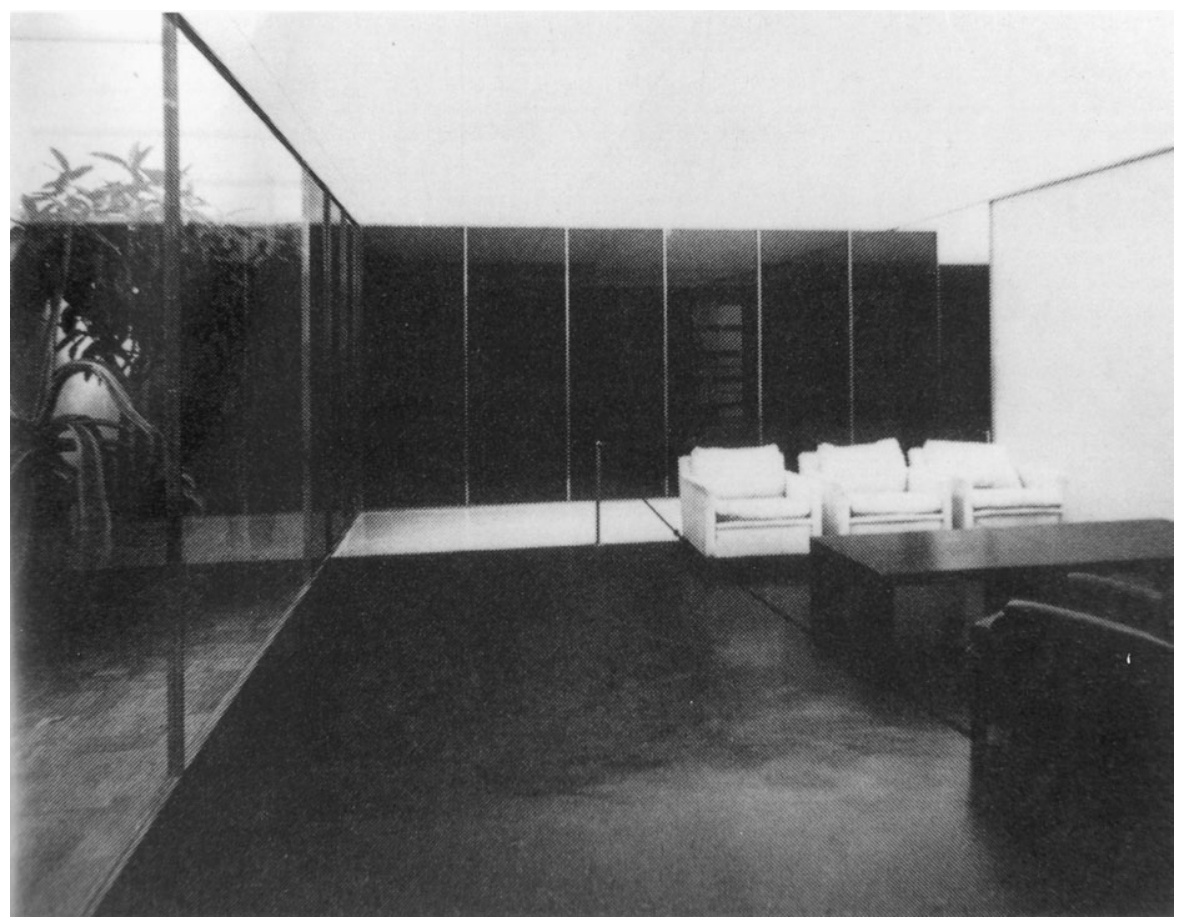

Exposición de la Werkbund. 1927. Glass Room, la Sala del Cristal.

(MCQUAID, Matilda: Lilly Reich, Designer and Architect. Nueva York, The Museum of Modern Art, 1996)

Tugendhat en Brno de 1928-29 y para el pabellón representativo de Alemania en la Exposición Internacional de Barcelona, de 1929.

El conocimiento y la sensibilidad de Reich por los materiales, era una cualidad, sabía sentir su naturaleza y cómo utilizarlos según sus leyes, esto hizo que utilizara pieles poco usuales, también elementos aparentemente secundarios, como alfombras y cortinas de diversos tejidos y colores arriesgados, que adquirieron un papel principal en la configuración del espacio.

Las telas, sus propiedades, sus colores, eran muy importantes para Reich. El trabajo con las telas fue una constante en toda su carrera. Desde sus primeros años, dedicada al diseño de moda, tenía un buen conocimiento de este material. Gracias a ella la tela se volvió a utilizar, pero pasó de ser un material de decoración a ser un material con el que se podía construir el espacio. Con el tiempo, Mies fue concediendo mayor importancia a estos aspectos del diseño para configurar sus espacios. 
A través de estos proyectos Mies Van der Rohe y Lilly Reich, consolidaron una nueva relación espacio - mobiliario. Crearon piezas pensadas para cada uno de los espacios en los que iban a estar situadas. El mobiliario fue cuidadosamente realizado conjuntamente por Mies y Reich en ambos proyectos. Con el mobiliario, se construía, se determinaba la configuración del espacio, por ello su colocación era exacta y precisa. Pequeños conjuntos de muebles se situaban sobre un plano horizontal, recortado sobre una superficie continua, una alfombra.

El trabajo de Mies y Reich, redefinió el concepto de espacio interior, como un espacio por el que se podía circular libremente. El espacio se convirtió en una cualidad esencial en sus proyectos.

Esta colaboración entre Mies van de Rohe y Lilly Reich en el diseño y acondicionamiento de mueble y de espacios interiores, se puso de manifiesto claramente durante la realización de las viviendas de la Exposición de Berlín, en 1931, La vivienda de nuestro tiempo. O también en los proyectos de las casas - patio, en los años treinta. Allí Lilly Reich pudo construir su primera vivienda, en solitario y contigua a una de Mies Van der Rohe, ambas

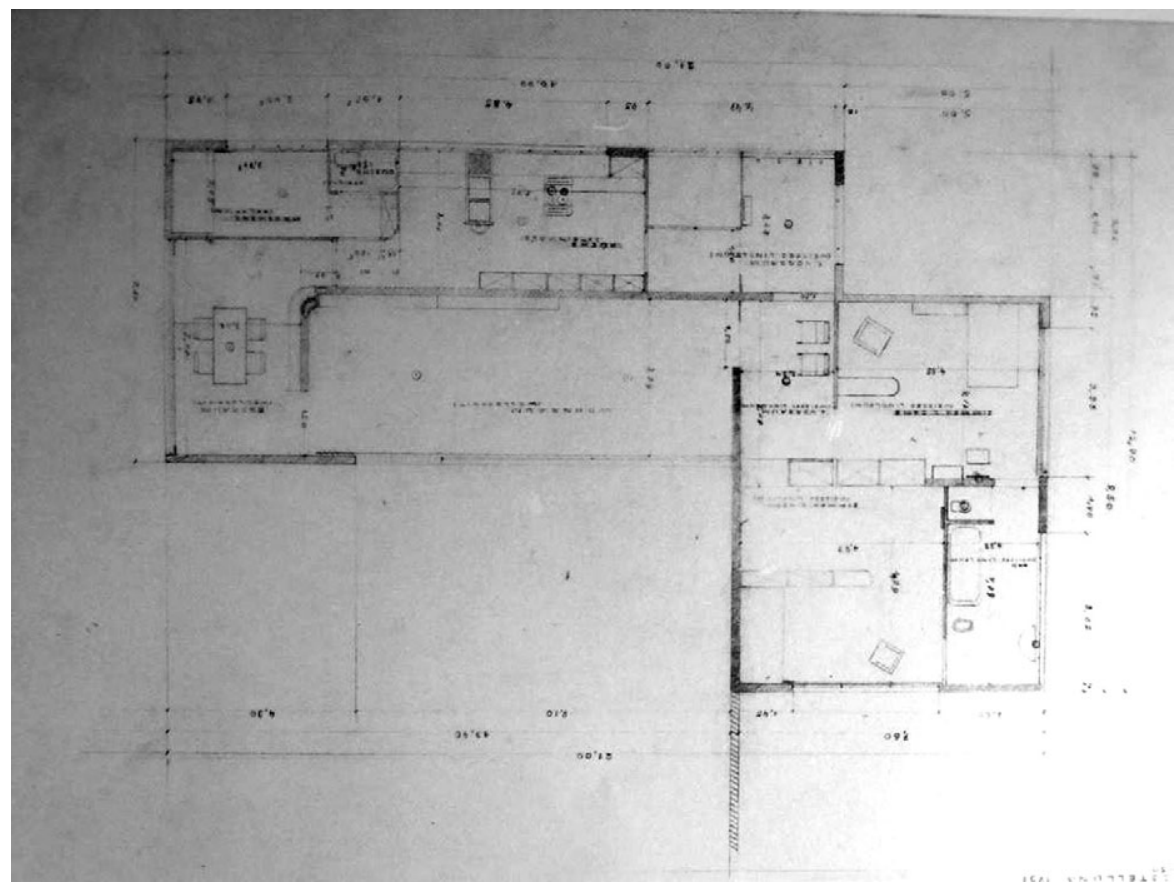

Planta Lilly Reich, croquis vivienda en planta baja. Exposición de Berlín 1931.

(Colecciones Garland de los archivos de Mies van der Rohe) 
situadas en la planta baja de la nave, halle 2, del recinto ferial de Berlín en la Reichskanzlerplatz.

El mobiliario estaba compuesto, tan solo, por lo imprescindible: librería, mesas y sillas que fueron diseñados especialmente por Reich para esta vivienda, y producidos como modelos LR.

La ausencia de compartimentación permitía que la luz llegara hasta el interior de la casa, las paredes blancas reflejaban esta luz aumentando la sensación de amplitud en el espacio. En los espacios de la casa que construyó Reich, para la exposición de Berlín, se podía apreciar la cualidad del vacío, que era entendido como ausencia de formas y objetos innecesarios. Así, se conseguía la reducción a lo esencial. También para la Exposición de Berlín, Lilly Reich proyectó el interior de dos apartamentos contiguos en la última planta de un bloque residencial, la Boarding-Haus. La primera, era una vivienda para una persona sola y la segunda una vivienda, para una pareja sin hijos. Unos programas habitacionales, poco convencionales para la época. En ellas puso en práctica la nueva organización del espacio interior. Los bocetos de Reich, para estas viviendas, muestran hasta cuatro tipos de estudios sobre variaciones de división espacial. Ensayó mediante la disposición de armarios y la colocación del mobiliario, con estos elementos construía los espacios.

El baño era el único elemento arquitectónico fijo, lo que permitía libertad en la distribución del resto del interior de las viviendas.

Aunque el conjunto del bloque de la Boarding-Haus, estaba concebido para la utilización de los servicios comunes, por lo que no era necesario incorporar cocina en las viviendas, Reich diseñó para este apartamento, un bloque compacto, exento que servía de almacenaje y cocina, y que además era

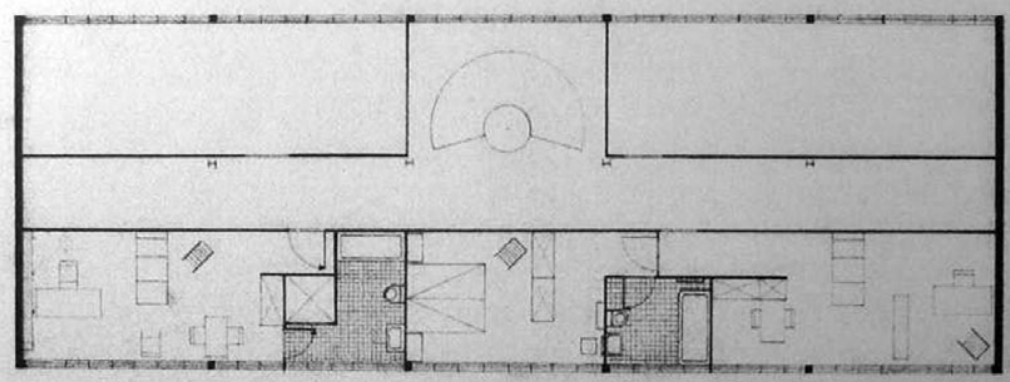

Lilly Reich planta viviendas contiguas de la Boarding-Haus.

(Colecciones Garland de los archivos de Mies van der Rohe) 

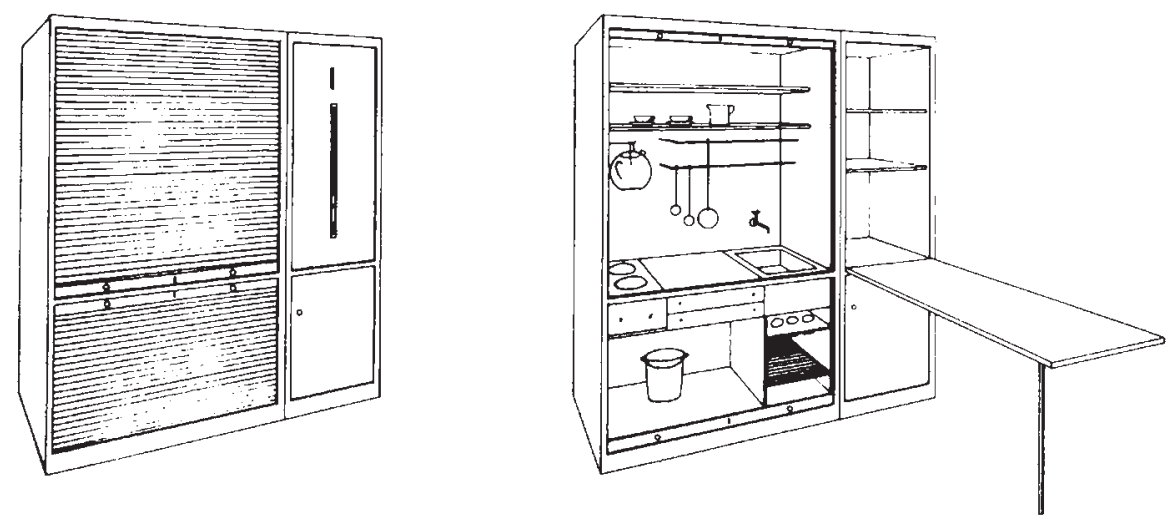

Lilly Reich. Bloque compacto armario cocina.

(MCQuAID, Matilda: Lilly Reich, Designer and Architect. Nueva York, The Museum of Modern Art, 1996)

el único elemento de compartimentación en el espacio, separando la sala de estar, del núcleo de baño.

La actividad de cocinar fue estudiada y organizada, con rigor, por Reich, para conseguir la máxima eficacia en el menor espacio posible. También estudió la función de almacenaje, pues el mueble permitía guardar los utensilios de cocina que se clasificaron por tamaño y se colgaron para optimizar la capacidad y hacer más fácil su acceso, además se podía extraer una tabla, para planchar y también guardar otros objetos. El espacio en Reich se definía mediante el mobiliario, con su colocación y su cualidad, forma y material, que eran estudiados minuciosamente al detalle.

Quedan en el archivo de Mies van der Rohe, entremezclados con sus dibujos, los que realizó Lilly Reich en solitario, con sello Atelier Reich. Entre ellos, se encuentran los estudios para el amueblamiento del apartamento para un soltero de Mies; llama la atención la precisión y el detalle del diseño de un armario, al igual que Charlotte Perriand, todo estaba medido y ordenado, muestra de la importancia concedida por su autora a esta pieza de la casa.

La mujer, desde su ámbito, la casa, al que había sido confinada, había tomado las riendas de la transformación para lograr el diseño de la casa para la nueva vida.

Charlotte Perriand, y Lilly Reich, fueron dos de esas mujeres que por su origen y formación conocían bien las restricciones de ese ámbito privado, e iniciaron la renovación desde el interior de la arquitectura, desde un elemento mínimo de la casa, el armario, que pasó de ser el símbolo de las tareas 


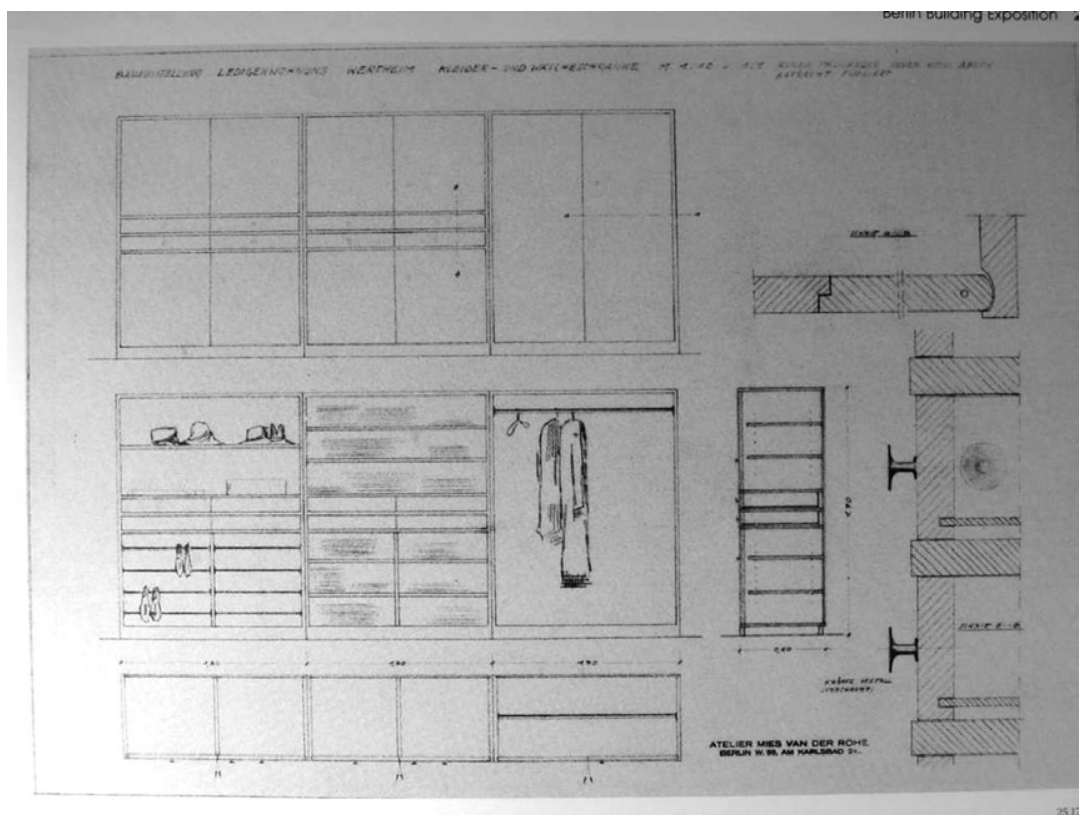

Lilly Reich. Croquis armario apartamento para un soltero. Exposición de Berlín 1931. (Colecciones Garland de los archivos de Mies van der Rohe)

domésticas de la mujer al elemento utilizado por la mujer para transformar la estructura de la vivienda y desde ahí poder plantear un nuevo tipo de relaciones espaciales y con ellas un cambio en la relación entre los habitantes.

Quizá todo comenzara con el diseño de un armario...

\section{Referencias Bibliográficas}

LE Corbusier: Precisiones. Barcelona, Poseidón, 1979.

MCQUAID, Matilda: Lilly Reich, Designer and Architect, Nueva York: The Museum of Modern Art, 1996.

MIES VAN DER ROHE, archivos, colecciones Garland.

NEUMEYER, Fritz: Mies van der Rohe: La palabra sin artificio. Reflexiones sobre arquitectura, 1922-1968. Madrid, Croquis, 1995.

PERriand, Charlotte: Una vie de création. París, Odile Jacob, 1998.

RÜEGG Arthur: Perriand Charlotte: Livre de Bord. 1928-1933. Basilea, Birkhäuser, 2004.

SENNET, Richard. La conciencia del ojo. Barcelona, Versal, 1991.

Vegara, Alejandro. Vermeer y el interior holandés. Madrid, Museo Nacional del Prado, 2003. 